\title{
FLUORIDE RELEASE FROM GLASS IONOMER CEMENTS CORRELATES WITH THE NECROTIC DEATH OF HUMAN DENTAL PULP STEM CELLS
}

\author{
Tatjana Kanjevac ${ }^{1}$, Marija Milovanovic ${ }^{2}$, Vladislav Volarevic ${ }^{2}$, Nebojsa Arsenijevic ${ }^{2}$, \\ ${ }^{1}$ Department for Preventive and Pediatric Dentistry, Faculty of Medicine, University of Kragujevac, \\ ${ }^{2}$ Centre for Molecular Medicine and Stem Cell Research, Faculty of Medicine University of Kragujevac
}

\begin{abstract}
Glass ionomer cements (GICs) are commonly used as restorative materials. The effect of GICs on different cell types varies. Stem cells from Human Exfoliated Deciduous teeth, SHED are a source for dental tissue regeneration. The necrosis and inflammation that eventually follows necrosis can disturb this regenerative process.

We tested seven GICs including Fuji I, Fuji II, Fuji VIII, Fuji IX, Fuji plus, Fuji triage and Vitrebond for their necrotic induction potential in human SHEDs. We also correlated these effects with eluate fluoride release. The toxicity of GICs was tested via a lactate dehydrogenase assay and flow cyto-
\end{abstract}

metric analysis of propidium iodide and Annexin $V$ stained cells. The concentration of fluoride was measured by HPLC. The Fuji I and Fuji II GICs had a significantly lower cytotoxic effect on SHEDs compared to other tested GICs, as evaluated by the LDH assay. The results obtained from the flow cytometric analyses were similar. The Fuji I and Fuji II eluates released the lowest concentrations of fluoride and induced the lowest percentages of SHED death. Fluoride release correlated with GIC cytotoxicity.

Keywords: glass ionomer cements, cytotoxicity, fluoride, Stem cells from Human Exfoliated Deciduous teeth

\section{INTRODUCTION}

Pulp has an important role in the formation of dentin. Dentin formation begins when dental pulp mesenchymal stem cells differentiate into odontoblasts and start the deposition of collagen matrix and subsequent mineralisation [1]. Dentin formation continues through life due to tooth aging, as well as in response to physical and/or chemical injuries [2]. The main goal of restorative dentistry is to restore teeth using adequate treatments that will protect pulp function. To avoid any additional damage to pulp tissue during operative procedures caused by the toxicity of restorative materials or the penetration of bacteria, several layers of a specific material between the restorative material and the dental tissue must be applied [3, 4]. Calcium hydroxide-based products, adhesive systems and glass ionomer cements (GICs) are typically used for this purpose. GICs were introduced by Wilson and Kent in 1971 as a mixture of a calcium or strontium alumino-fluoro-silicate glass powder (base) and a water-soluble polymer (acid) [5]. Several variations of glassionomer materials were subsequently developed. Later variants of GICs demonstrated enhanced flexural strength, diametral tensile strength, elastic modulus and wear resistance, but their main disadvantage is higher cytotoxicity in comparison with conventional GICs. The responses to GICs differ by cell type. Thus, it is important to evaluate the cytoxicity of GICs to SHEDs [6-9].

It has been suggested that the pattern of cell death pattern could be an important method of evaluating the irritation potential of dental materials. Apoptotic cells are removed by phagocytosis and with little inflammatory response, in contrast to the inflammation and injury to the surrounding tissues induced by the necrotic process [10]. As dental pulp stem cells are the main source for dental tissue regeneration, it is important to evaluate the potential of GICs to induce necrosis of SHEDs and subsequent inflammation in the surrounding tissue. We evaluated the potential of seven commonly used biomaterials, Fuji I, Fuji II, Fuji VIII, Fuji IX, Fuji Plus, Fuji Triage and Vitrebond, to the induce necrosis of human SHEDs. 


\section{MATERIALS AND METHODS}

\section{Cell culture}

Human SHEDs were purchesed from AllCells (Emeryville, California USA). The cells were cultured in Dulbecco's Modified Eagle Medium (DMEM) containing 10\% FBS, $100 \mathrm{IU} / \mathrm{mL}$ penicillin $\mathrm{G}$ and $100 \mu \mathrm{g} / \mathrm{mL}$ streptomycin (Sigma-Aldrich Chemical, Munich, Germany). SHEDs passaged 6 times were used throughout these experiments.

\section{Tested materials}

The cytotoxic effects of seven glass ionomer cements, Fuji I, Fuji II, Fuji VIII, Fuji IX, Fuji plus, Fuji Triage (GC America, Alsip, IL, USA) and Vitrebond (3M ESPE, London, UK), were tested in this study. Separate GIC samples were prepared according to the manufacturers' directions at room temperature and then placed into open plastic rings $5 \mathrm{~mm}$ in diameter by $2 \mathrm{~mm}$ deep. After consolidation, the samples were removed from rings and dry heat sterilised for 1 hour at $170{ }^{\circ} \mathrm{C}$. The samples were then incubated in complete culture medium $(150 \mu \mathrm{L}$ per sample) for 72 hours at the $37^{\circ} \mathrm{C}$ and in a $5 \% \mathrm{CO}_{2}$ atmosphere. The sample dimensions and immersion conditions were chosen to approximate the GIC mass and the dentin-exposed surface area typically used in restorative dentistry patient procedures. The medium exposed to each GIC sample was used for testing in a cell-culture system.

\section{Evaluation of toxicity using the LDH assay}

The cytotoxicity of GICs was examined via a Cytotoxicity Detection Kit (LDH) (Roche Applied Science). SHEDs were diluted with DMEM medium to $1 \times 10^{5}$ cells $/ \mathrm{mL}$, and aliquots $\left(1 \times 10^{4}\right.$ cells $\left./ 100 \mu \mathrm{L}\right)$ were placed in individual wells in 96-well plates. The next day, the media were exchanged with media exposed to a GIC mixed with fresh medium in a $1: 1$ ratio to a final volume of $100 \mu \mathrm{L}$. Each eluate was tested in triplicate. Two groups of control wells were prepared: low control (medium was exchanged with fresh medium) and high control (medium was exchanged with medium containing $1 \%$ Triton $\mathrm{X}$ ). The cells were incubated at $37^{\circ} \mathrm{C}$ in a $5 \% \mathrm{CO}_{2}$ incubator for $24 \mathrm{~h}$. After treatment, the supernatant $(100 \mu \mathrm{L})$ was transferred to a new plate and incubated with an equivalent volume of substrate solution. After incubating the plates for 30 minutes at RT, $50 \mu \mathrm{l} /$ well of stop solution was added, and the plates were spectrophotometrically examined at $450 \mathrm{~nm}$. The percentage of dead cells was calculated using the formula:

$\%$ of dead cells $=$

(exp. value-low control)/(high control-low control) x 100

\section{Apoptosis assay}

SHEDs exposed to GIC eluates were examined by flow cytometry using Annexin V FITC (BD Pharmingen, San Jose, CA, USA) Propidium Iodide (Sigma-Aldrich Chemical Company, Munich, Germany) staining. After the SHEDs reached subconfluency, the flask medium was replaced with mixture of medium exposed to GICs and fresh, complete DMEM (ratio 1:1) (volume, $4 \mathrm{~mL}$ ). The SHEDs exposed to the GICs eluate were incubated at $37^{\circ} \mathrm{C}$ in a $5 \% \mathrm{CO}_{2}$ atmosphere for $24 \mathrm{~h}$. The cultured cells were washed twice with cold phosphate-buffered saline (PBS, Sigma Aldrich) and resuspended in 1x binding buffer (10x binding buffer: 0.1 M Hepes/ $\mathrm{NaOH}$ (pH 7.4), 1.4 $\left.\mathrm{M} \mathrm{NaCl}, 25 \mathrm{mM} \mathrm{CaCl}_{2}\right)$ at a concentration of $1 \times 10^{6} / \mathrm{mL}$. Annexin FITC $(5 \mu \mathrm{L})$ and propidium iodide (PI) $(5 \mu \mathrm{L}, 50$ $\mu \mathrm{g} / \mathrm{ml}$ in PBS) were added to $100 \mu \mathrm{L}$ of the cell suspension and incubated for $15 \mathrm{~min}$ at room temperature $\left(25^{\circ} \mathrm{C}\right)$ in the dark. After incubation, $400 \mu \mathrm{L}$ of $1 \mathrm{x}$ binding buffer was added to each tube. The stained cells were analysed within 1 hour using FACS Calibur (BD, San Jose, USA) and CellQuest software. Because Annexin V FITC staining precedes the loss of membrane integrity that accompanies the later stage identified by PI, Annexin V FITC positive and PI negative staining indicates early apoptosis, whereas Annexin V FITC negative and PI negative staining indicates cell viability. Cells that are in late apoptosis or already dead are both Annexin V FITC and PI positive, and dead cells are PI positive only [11].

Quantification of fluoride in medium exposed to GIC

The fluoride (F) concentrations of each eluate were assayed by high performance liquid chromatography using a Chromeleon ${ }^{\circledR}$ Chromatography Workstation (Dionex, Wien, Austria) equipped with a GP50 gradient pump, conductivity detector, ASRS ultra $4 \mathrm{~mm}$. An Ionpac AS15 column and an AG15 guard column were used. Potassium hydroxide was used as the eluent. The flow rate was $1.0 \mathrm{~mL} / \mathrm{min}$. All results were analysed on Chromeleon 6.7 Chromatography Management Software.

\section{Statistical Analysis}

The cytotoxicity was expressed as mean + standard deviation. One-way ANOVA tests and linear regression were used to analyse the data. A p $<0.05$ was considered statistically significant.

\section{RESULTS:}

\section{LDH assay}

Stem cell death, as evaluated by an LDH test 24 hours after incubation in GIC eluates, indicated very similar cytotoxic effects for the Fuji VIII, Fuji IX, Fuji plus, Fuji triage and Vitrebond GICs. These eluates induced necrosis in approximately $50 \%$ of the SHEDs. The Fuji I $(25.14 \%$ dead cells) and Fuji II (28.56\% dead cells) GICs demonstrated significantly less cytoxicity (Figure 1).

\section{Fluoride release}

We wanted to know if the leaching of ionic components into the biomaterial eluates could account for the cytotoxic effect of the GICs. For that purpose, one of the major ions present in all tested GICs, F-, was quantified in the eluates (Figure 2). There was a strong correlation between the cytotoxic effects of GICs and fluoride release. Pear- 
son's correlation coefficient $\left(\mathrm{r}^{2}\right)$ value demonstrated a high correlation between F- release and cytotoxicity $\left(r^{2}=0.848\right.$, $\mathrm{p}=0.003$ ). The more cytotoxic GICs (Fuji Plus, Vitrebond, Fuji IX, Fuji triage and Fuji VIII) released more F- then the other tested GICs. The less cytotoxic materials (Fuji I and Fuji II) released less F-.

\section{Apoptosis assay}

To more closely investigate the effects of GICs on human SHEDs, we performed apoptosis assays. These assays confirmed the results obtained by the LDH test (Figure 3). All GICs induced permeabilisation of the SHED membranes (propidium iodide-positive cells). The highest percentages of dead cells were recorded after treatment with Fuji VIII, Fuji IX or Vitrebond (Figure 3). In addition, there was a good correlation between the percentage of dead cells as measured by the apoptosis assay and fluoride release $\left(\mathrm{r}^{2}=0.717, \mathrm{p}=0.016\right)$.

\section{DISCUSSION}

The biological compatibility of dental materials is essential for avoiding or limiting pulp tissue irritation or degeneration. GIC formulations contain organic monomers and different ions that may diffuse through the dentin tubules and reach the pulp tissue. These ions can affect the vitality of the odontoblast layer and interfere with pulp homeostasis and healing $[12,13]$. SHEDs are adult stem cells that are able to regenerate a dentin-pulp-like complex, composed of mineralised matrix with tubules lined with odontoblasts and fibrous tissue containing blood vessels in an arrangement similar to the dentin-pulp complex found in normal human teeth [14]. Dentin formation continues through life in response to physical and/or chemical injuries and tooth aging. As SHEDs are involved in the damaged pulp repair processes, we selected them as an adequate cell culture system for testing the effects of GICs.

To explore the cell damage potential of GICs, we used an LDH assay. Lactate dehydrogenase is a cytoplasmatic enzyme released after cell membrane disruption. The LDH assay measures the activity of LDH in cell supernatants, thus, indirectly measuring cell death associated with a loss of membrane integrity [15]. The results of the LDH assay indicated that eluates from the Fuji VIII, Fuji IX, Fuji plus, Fuji Triage and Vitrebond samples were highly cytotoxic to human SHEDs (Figure 1), and there was no significant difference between them. The Fuji I and Fuji II eluates were slightly less cytotoxic, suggesting better biocompatibility. Our results are in agreement with previous reports showing that GICs are toxic to dental pulp [16] and pluripotent mesenchymal precursor cells [17].

GICs eluates induced similar toxicity as evaluated by flow cytometric analysis of PI-stained cells. These data indicated that the highest percentage of damaged cells was attained after treatment with Fuji plus, Fuji IX or Vitrebond GICs, a moderate percentage was attained after treatment with Fuji



Figure 1. Stem cell necrosis as evaluated by the LDH assay. Each column represents the percentage of dead cells (mean value and standard deviation of 3 experiments with 3 replicates)

The least cytotoxic GICs were Fuji I (25.14\%) and Fuji II (28.56\%), while Fuji Plus (52.48\%), Vitrebond (54.18\%), Fuji VIII (49.13\%), Fuji IX (45.20\%) and Fuji Triage (53.68\%) demonstrated higher cytotoxic effects on SHEDs. There was a statistically significant difference between Fuji I and Vitrebond $(\mathrm{p}=0.04)$.

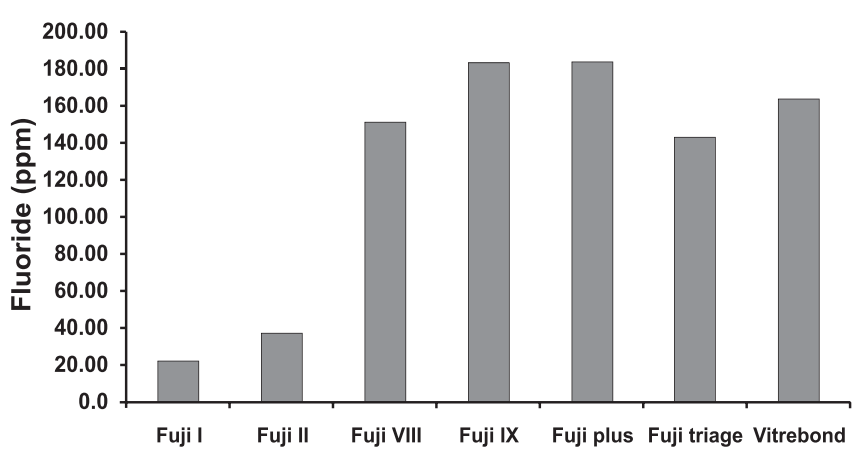

Figure 2. Quantification of Fluoride in the eluates of tested GICs.

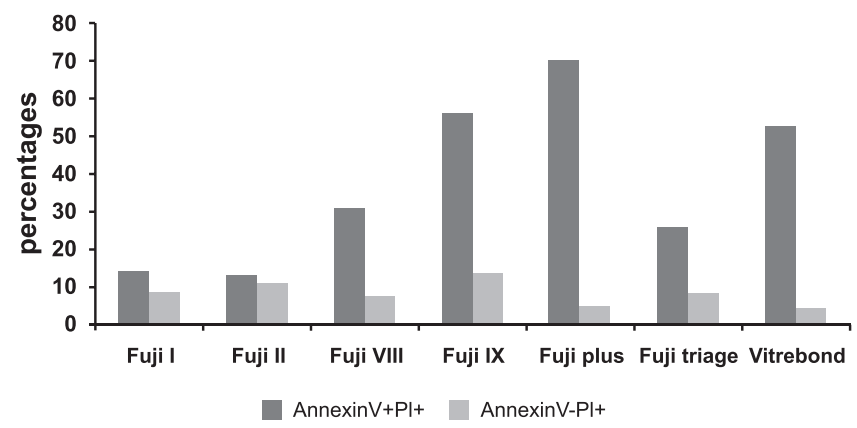

Figure 3. The percentage of dead cells as evaluated by the apoptosis assay. The highest percentage of dead cells was attained after treatment with Fuji IX (69.6\%), Vitrebond (57.20\%) or Fuji Plus (74.9\%). A moderate percentage of dead cells was attained after treatment with Fuji VIII (38.40\%) or Fuji Triage (34.10\%). The lowest percentage of necrosis was attained after treatment with Fuji I (22.8\%) or Fuji II (24.3\%). The results of a representative experiment are presented. 
triage or Fuji VIII GICs and the lowest percentage was attained after treatment with Fuji I or Fuji II GICs (Figure 2).

These differences in cytotoxic effects between different GICs on human SHEDs appear to be related to the amount of fluoride released. The most toxic GICs, Fuji Plus, Vitrebond and Fuji VIII, released a higher amount of F anions than the other tested materials (Figure 3). In addition, low levels of released fluoride were noticed in the Fuji I and Fuji II eluates, which were the least cytotoxic GICs (Figure 2). Although it is known that the main advantage of using GICs as adhesive restorative materials is the long-term antibacterial effect due to fluoride release $[3,9,18]$, we are the first group to demonstrate that the fluoride release of GICs has a direct correlation with cytotoxic effects on human SHEDs. GICs achieve maximum fluoride release $24 \mathrm{~h}$ after the initial setting [19], and that fluoride release has a significant potential for inducing pulpal toxicity [20]. The potential of fluoride anions to induce necrosis of Swiss-strain mouse hepatocytes [21] and primary culture of rat thymocytes [22] has been reported previously but in this study, we are first to show that fluoride release directly correlates with GIC cytotoxic effects in human SHEDs.

\section{Acknowledgements}

This study was supported by Ministry of Science and Technology, Republic of Serbia (grants: ON175069, ON175071 and ON175103) and by Faculty of Medicine University of Kragujevac (grant: JP26/10).

\section{REFERENCES:}

1. Almushayti A, K Narayanan K, A E Zaki A E, George A. Dentin matrix protein 1 induces cytodifferentiation of dental pulp stem cells into odontoblasts. Gene Therapy (2006) 13, 611-620

2. Pashley DH. Dynamics of the pulpo-dentin comples. Crit Rev Oral Biol Med. 1996;7(2):104-33.

3. Modena K, Casas Apayco L, Atta M, Costa C, Hebling J, Sipert C, Navarro M, Santos C. Cytotoxicity and biocompatibility of direct and indirect pulp capping materials. Journal of Applied Oral Science 2009; 17:544-554.

4. Briso ALF, Rahal V, Mestrener SR, Dezan E Jr. Biological response of pulps submitted to different capping materials. Brazilian Oral Research 2006; 20:219-225.

5. Wilson AD, Kent BE. The glass ionomer cement, a new transluscent dental filling material. Journal of applied chemistry \& biotechnology 1971; 21:313.

6. Matsuya S, Maeda T, Ohta M. IR and NMR analyses of hardening and maturation of glass-ionomer cement. Journal of Dental Research 1996; 75:1920-1927.

7. Burgess J, Norling M, Summit J. Resin ionomer restorative materials: the new generation. Journal of Esthetic and Restorative Dentistry 1994; 6:207-215.

8. Wasson EA. Reinforced glass-ionomer cements - a review of properties and clinical use. Clinical Materials1993; 12:181-190.
9. Mount GJ. Glass-ionomer cements: past, present and future. Operative Dentistry 1994; 19: 82-90

10. Shacter E, Williams J, Hinson R, Sentürker S, Lee Y. Oxidative stress interferes with cancer chemotherapy: inhibition of lymphoma cell apoptosis and phagocytosis. Blood,, 2000; 96 (1): 307-313

11. Vermes I, Haanen C, Steffens-Nakken H, Reutelingsperger C. A novel assay for apoptosis. Flow cytometric detection of phosphatidylserine expression on early apoptotic cells using fluorescein labeled Annexin V. J Immunol. Methods 1995; 184: 39-51.

12. Bouillaguet S. Biological risks of resin-based materials to the dentin pulpcomplex. Crit Rev Oral Biol Med; 2004; 15:47-60.

13. Teti G, Mazzotti G, Zago M et al. HEMA down-regulates procollagen alpha1 type I in human gingival fibroblasts. J Biomed Mater Res; 2009; 90:256-62.

14. Gronthos S, Mankani M, Brahim J, Robey PG and Shi S. Postnatal human dental pulp stem cells (SHEDs) in vitro and in vivo. Proc Natl Acad Sci U S A; 2000; 97:13625-30.

15. Korzeniewski C, Callewaert D. An enzyme-release assay for natural cytotoxicity. Journal of Immunological Methods, 1983; 64 (3): 313-320.

16. Stanislawski L, Daniau X, Lauti A, Goldberg M. Factors responsible for pulp cell cytotoxicity induced by resinmodified glass-ionomer cements. Journal of Biomedical Materials Research 1999; 48:277-288.

17. Imazato S, Horikawa D, Takeda K, Kiba W, Izutani N, Yoshikawa R, Hayashi M, Ebisu S and Nakano T. Proliferation and differentiation potential of pluripotent mesenchymal precursor $\mathrm{C} 2 \mathrm{C} 12$ cells on resin-based restorative materials. Dental Materials Journal 2010; 29: 341-346

18. Chan C, Lan W, Chang M, Chen Y, Lan W, Chang H. Effects of TGF betas on the growth, collagen synthesis and collagen lattice contraction of human dental pulp fibroblasts in vitro. Archives of Oral Biology 2005; 50:469-479.

19. dos Santos RL, Pithon MM, Vaitsman DS, Araújo MT, de Souza MM, Nojima MG. Long-term fluoride release from resin-reinforced orthodontic cements following recharge with fluoride solution. Brazilian Dental Journal 2010; 21: 98-103.

20. Chang YC, Chou MY. Cytotoxicity of fluoride on human pulp cell cultures in vitro. Oral Surgery Oral Medicine Oral Pathology Oral Radiology and Endodontics 2001; 91: 230-234.

21. J. Ghosh, J. Das, P. Manna, P.C. Sil, Cytoprotective effect of arjunolic acid in response to sodium fluoride mediated oxidative stress and cell death via necrotic pathway, Toxicol. In Vitro 2008; 22: 1918-1926.

22. H. Matsui, M. Morimoto, K. Horimoto, Y. Nishimura, Some characteristics of fluoride-induced cell death in rat thymocytes: cytotoxicity of sodium fluoride, Toxicol. In Vitro 2007; 21: 1113-1120. 